\title{
Production of D-Glyceric Acid by a Two-step Culture Strategy Based on Whole-cell Biocatalysis of Acetobacter tropicalis
}

\author{
B. Wang, ${ }^{\mathrm{a}, \mathrm{e}}$ Y. Pu, ${ }^{\mathrm{b}}$ H. G. Gerken, ${ }^{\mathrm{c}}$ Y. Xie, ${ }^{\mathrm{d}}$ L. Lin,,${ }^{\mathrm{a}}$ H. Chen, ${ }^{\mathrm{b}}$ and Y. Lu ${ }^{\mathrm{b},{ }^{,}}$ \\ ${ }^{a}$ College of Oceanology and Food Science, Quanzhou Normal University, \\ Quanzhou 362000, China \\ ${ }^{\mathrm{b} C o l l e g e ~ o f ~ C h e m i s t r y ~ a n d ~ C h e m i c a l ~ E n g i n e e r i n g, ~ X i a m e n ~ U n i v e r s i t y, ~}$ \\ Xiamen 361005, China \\ 'Arizona Center for Algal Technology and Innovation, Arizona State \\ University, Mesa, Arizona 85212, USA \\ ${ }^{\mathrm{d} C o l l e g e}$ of Biological Science and Engineering, \\ Fuzhou University, Fuzhou 350108, China \\ ${ }^{\mathrm{e}}$ Fujian Province Key Laboratory for the Development of Bioactive \\ Material from Marine Algae, Quanzhou 362000, China
} doi: 10.15255/CABEQ.2017.1181

Original scientific paper

Received: July 1, 2017 Accepted: February 19, 2018

\begin{abstract}
D-Glyceric acid (D-GA) is a promising chemical for minimizing the toxic effect of acetaldehyde. It has been successfully produced by bioprocesses using glycerol as a substrate. However, high concentrations of glycerol are not beneficial for cell growth. A two-step culture strategy was employed to deal with the ambivalent culture conditions between the growth of Acetobacter tropicalis and the biosynthesis of D-GA. The first stage focuses on biomass accumulation with low initial glycerol concentration; the second stage provides D-GA accumulation through whole-cell biocatalysis. Approximately 2-fold of D-GA yield and 4.5-fold of D-GA productivity were gained by the two-step culture strategy compared to the traditional fermentation with $150 \mathrm{~g} \mathrm{~L}^{-1}$ of glycerol. Our results also showed that $A$. tropicalis was able to catalyze the conversion of glycerol to D-GA in the presence of up to $10 \%$ methanol. These findings have important implications to enhance D-GA yield by strategy optimization and reduce its cost.
\end{abstract}

Key words:

glyceric acid, Acetobacter, two-step culture, biocatalysis, fermentation, cost-effective production

\section{Introduction}

Glyceric acid (2,3-dihydroxypropionic acid; GA) is an important intermediate and organic synthetic material, which is widely used in chemical products synthesis ${ }^{1}$, cosmetics ${ }^{2}$, and pharmaceuticals $^{3}$. D-GA has biological functions such as accelerating ethanol and acetaldehyde oxidation in rats $^{4}$ and enhancing the viability of ethanol-dosed gastric cells $\mathrm{s}^{3}$. It is also a liver stimulant and cholesterolytic agent in $\operatorname{dogs}^{5,6}$. Therefore, D-GA is a promising chemical for minimizing the toxic effect of acetaldehyde, the metabolite of ethanol.

High purity of D-GA can be gained by microbial oxidation such as fermentation with high concentration of glycerol ${ }^{2,7}$. However, high glycerol

"Corresponding author: Yinghua Lu (ylu@xmu.edu.cn); Tel: +86-592-2183751, Fax: +86-592-2186400 concentration may have negative effects on cell growth, and the complex compositions of fermentation broth increase the difficulties in D-GA purification. Although desalting electrodialysis was shown to be useful in separating D-GA from broth ${ }^{8}$, the equipment is costly. Enzyme catalysts can avoid the considerable investment in equipment, but the enzyme itself is also costly. Compared with isolated enzymes, whole cell catalysts can be much more readily and inexpensively prepared, and enzymes in the whole cells are more stable than free enzymes as they are protected inside cells. Additionally, the use of pure substrate with whole-cell catalyst should have fewer conflicts between cell growth and production as compared to fermentation. Recently, whole-cell biocatalysis has been successfully applied to produce biodiesels ${ }^{9}$, 6-O-propionyl-D-glu$\cos ^{10}$, fructose laurate esters ${ }^{11}$, and other commercial chemicals. Multistage fermentation was shown 
to be an effective method to facilitate both cell growth and product accumulation ${ }^{12,13}$. In this study, a two-step culture strategy was utilized to enhance D-GA yield without cell growth inhibition in $A$. tropicalis: low glycerol medium was first applied for cell growth (first stage), and then whole-cell biocatalysis was performed using glycerol as the only substrate to synthesize D-GA (second stage).

Glycerol, the substrate for D-GA, is the main by-product of the biodiesel fuel (BDF) production process. With the rapid worldwide increase in BDF production, glycerol becomes abundant, which leads to a dramatic decrease in price ${ }^{14}$. Therefore, biological conversion of glycerol from the BDF process into D-GA is not only an economic use of glycerol, but also a commendable method to cut the cost of D-GA production. However, the raw glycerol derived from BDF production always includes methanol, which is costly to remove by evaporation during BDF manufacturing. Therefore, the use of raw glycerol containing methanol is economically preferable, necessitating the development of technology using glycerol that contains methanol ${ }^{15}$. A methanol-resistant mutant of $G$. frateurii was successfully constructed to produce D-GA from $5 \%$ (v/v) methanol-containing glycerol medium ${ }^{16}$. However, few studies of methanol resistant ability of $A$. tropicalis have been reported. Therefore, the influence of methanol-containing glycerol on D-GA biosynthesis in A. tropicalis in the whole-cell biocatalysis process was also examined in this study.

\section{Materials and methods}

\section{Strains and culture conditions}

A. tropicalis CHM061701 (available in China General Microbiological Culture Collection Center) was first cultivated in 250-mL Erlenmeyer flasks containing $50 \mathrm{~mL}$ of glucose medium ( $\mathrm{pH} 6.5)$ containing $5 \mathrm{~g} \mathrm{~L}^{-1}$ glucose, $5 \mathrm{~g} \mathrm{~L}^{-1}$ polypeptone, $5 \mathrm{~g} \mathrm{~L}^{-1}$ yeast extract, $1 \mathrm{~g} \mathrm{~L}^{-1} \mathrm{MgSO}_{4} \cdot 7 \mathrm{H}_{2} \mathrm{O}$ at $30{ }^{\circ} \mathrm{C}$, and $200 \mathrm{rpm}$ for $24 \mathrm{~h}$. This was used as seed culture for the traditional culture and two-stage culture.

\section{Traditional culture}

Two-and-a-half $\mathrm{mL}$ seed culture (inoculum volume: $5 \%$ of glycerol medium) was transferred to $250-\mathrm{mL}$ Erlenmeyer flasks containing $50 \mathrm{~mL}$ of glycerol medium $\left(\mathrm{pH}\right.$ 6.5) consisting of $5 \mathrm{~g} \mathrm{~L}^{-1}$ polypeptone, $5 \mathrm{~g} \mathrm{~L} \mathrm{~L}^{-1}$ yeast extract, $1 \mathrm{~g} \mathrm{~L}^{-1}$ $\mathrm{MgSO}_{4} \cdot 7 \mathrm{H}_{2} \mathrm{O}, 0.9 \mathrm{~g} \mathrm{~L}^{-1} \mathrm{KH}_{2} \mathrm{PO}_{4}, 0.1 \mathrm{~g} \mathrm{~L}^{-1} \mathrm{~K}_{2} \mathrm{HPO}_{4}$, and varying concentrations of glycerol $\left(50 \sim 200 \mathrm{~g} \mathrm{~L}^{-1}\right)$, and incubated at $30^{\circ} \mathrm{C}$ on a rotary shaker $(200 \mathrm{rpm})$ for $5 \mathrm{~d}$.

\section{Two-stage culture}

Culture stage (first stage): This step was similar to the traditional culture. Two-and-a-half $\mathrm{mL}$ seed culture was transferred to $250-\mathrm{mL}$ Erlenmeyer flasks containing $50 \mathrm{~mL}$ of glycerol medium $(\mathrm{pH}$ 6.5) with $50 \mathrm{~g} \mathrm{~L}^{-1}$ of glycerol, and incubated at $30{ }^{\circ} \mathrm{C}$ on a rotary shaker $(200 \mathrm{rpm})$ for $60 \mathrm{~h}$. The cells were then harvested for the second stage.

Whole-cell biocatalysis stage (second stage): The cells from the first stage were harvested by centrifugation at 10,000 rpm for $5 \mathrm{~min}$, and washed twice with $0.9 \% \mathrm{NaCl}$ to remove residual culture nutrients. The cells were resuspended in different concentrations of glycerol (normally $150 \mathrm{~g} \mathrm{~L}^{-1}$ ), and the $\mathrm{OD}_{600}$ of this solution was normalized to 5 . Then $50 \mathrm{~mL}$ of this glycerol solution was inoculated in a 250-mL Erlenmeyer flask, and the whole-cell biocatalysis process was carried out at $28{ }^{\circ} \mathrm{C}$ and 200 $\mathrm{rpm}$ for $48 \mathrm{~h}$. Each experiment was carried out in triplicate.

\section{Quantification of glycerol, D-GA and dihydroxyacetone (DHA)}

Both of the Glycerol and D-GA contents were analyzed by high-performance liquid chromatography (HPLC) equipped with a Shodex SH1011 Column, and monitor by RID detector ${ }^{17}$. The column was maintained at $50{ }^{\circ} \mathrm{C}$. The mobile phase was $5 \mathrm{mM} \mathrm{H}_{2} \mathrm{SO}_{4}$ solution and the flow rate was 0.8 $\mathrm{mL} \min ^{-1}$.

DHA was quantified by the visible spectrophotometric method according to Liu ${ }^{18}$. Briefly, $1-\mathrm{mL}$ samples were mixed with $9 \mathrm{~mL} 1 \%$ (w/v) diphenylamine reagent (diphenylamine dissolved in sulfuric acid/acetic acid solution $(1: 9, \mathrm{v} / \mathrm{v}))$ and incubated in boiling water for $20 \mathrm{~min}$. The samples were then cooled to room temperature and the absorbance at $615 \mathrm{~nm}$ was measured immediately.

\section{Results and discussion}

\section{Effect of glycerol concentrations on $A$. tropicalis growth and D-GA accumulation}

To examine the effect of glycerol concentration on cell growth and D-GA accumulation in $\mathrm{A}$. tropicalis CHM061701, glycerol was applied as carbon source to incubate A. tropicalis CHM061701. As shown in Fig. 1, A. tropicalis CHM061701 grew better in medium with lower concentrations of glycerol $\left(50 \mathrm{~g} \mathrm{~L}^{-1}\right.$ and $\left.100 \mathrm{~g} \mathrm{~L}^{-1}\right)$. The cells entered the exponential growth phase after inoculation for $12 \mathrm{~h}$, and entered stationary phase at $72 \mathrm{~h}$ (Fig. 1a). The maximum dry cell weight (DCW) gained in these two cultures was $9.65 \mathrm{~g} \mathrm{~L}^{-1}$ and $7.55 \mathrm{~g} \mathrm{~L}^{-1}$, respectively. Cells grown in culture with $150 \mathrm{~g} \mathrm{~L}^{-1}$ and 

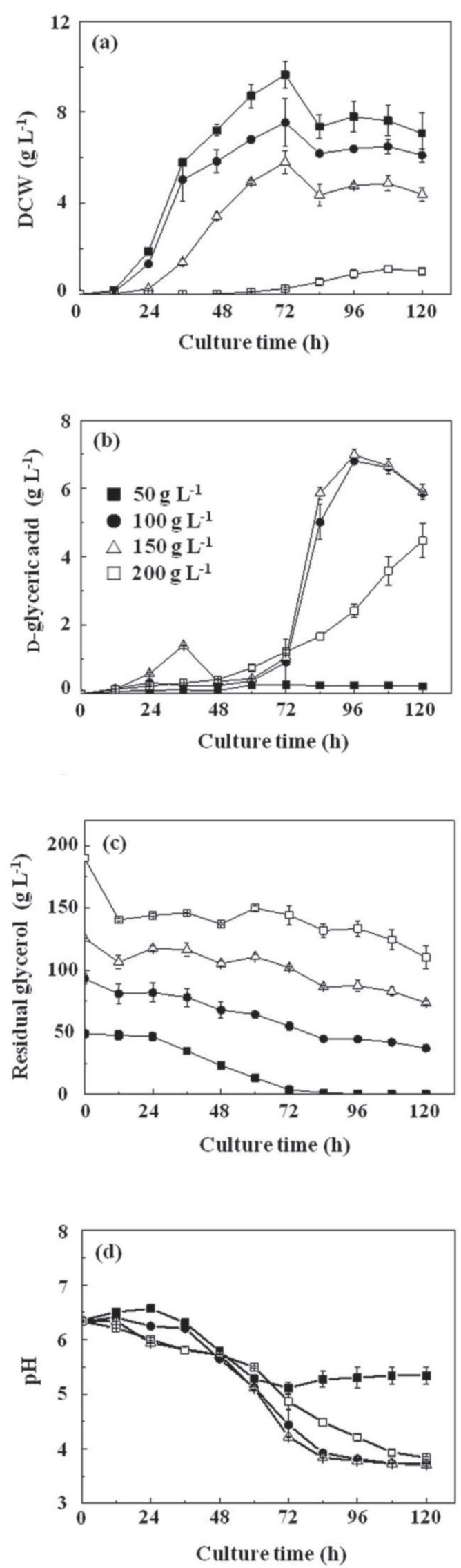

Fig. 1 - Effect of initial glycerol concentrations on cell growth and D-GA yield (a) DCW; (b) D-GA; (c) residual glycerol; (d) $\mathrm{pH}$
$200 \mathrm{~g} \mathrm{~L}^{-1}$ glycerol experienced a rather long lag phase, $24 \mathrm{~h}$ and $60 \mathrm{~h}$, respectively. Total biomass decreased with increasing initial glycerol concentration, and only $1.02 \mathrm{~g} \mathrm{~L}^{-1} \mathrm{DCW}$ was harvested in culture with $200 \mathrm{~g} \mathrm{~L}^{-1}$ glycerol, which was only $10.6 \%$ of that with $50 \mathrm{~g} \mathrm{~L}^{-1}$ initial glycerol. These results indicated that more than $50 \mathrm{~g} \mathrm{~L}^{-1}$ glycerol exerted a negative effect on the growth of $\mathrm{A}$. tropicalis. Thus, a lower initial glycerol concentration is required to promote cell growth and achieve a relatively high DCW. However, D-GA was undetectable in cultures with $50 \mathrm{~g} \mathrm{~L}^{-1}$ glycerol which was the best condition for cell growth. D-GA biosynthesis occurred at glycerol concentrations above $100 \mathrm{~g} \mathrm{~L}^{-1}$ (Fig. 1b). The maximal D-GA yield $\left(6.98 \mathrm{~g} \mathrm{~L}^{-1}\right)$ was gained in the culture with $150 \mathrm{~g} \mathrm{~L}^{-1}$ glycerol at 96 $\mathrm{h}$, and the D-GA productivity of $A$. tropicalis was $1.45 \mathrm{~g} \mathrm{~L}^{-1} \mathrm{DCW}$. Interestingly, the D-GA productivity increased with increasing initial glycerol concentration. In the culture with $200 \mathrm{~g} \mathrm{~L}^{-1}$ glycerol, the productivity D-GA was up to $4.39 \mathrm{~g} \mathrm{~g}^{-1} \mathrm{DCW}$, however, the cell growth was inhibited severely in this condition (Fig. 1a). These results showed that a high concentration of glycerol was essential for A. tropicalis to accumulate D-GA, though it was inhibitory towards cell growth.

All glycerol concentrations in cultures decreased with cell growth (Fig. 1c). In cultures with $50 \mathrm{~g} \mathrm{~L}^{-1}$ glycerol, glycerol concentration decreased corresponding to cell growth (logarithmic phase), and showed little decrease during stationary phase. However, glycerol concentrations continued to decrease during stationary phase in cultures with glycerol above $100 \mathrm{~g} \mathrm{~L}^{-1}$. This indicated that glycerol contributed to both cell growth and D-GA biosynthesis in medium with above $100 \mathrm{~g} \mathrm{~L}^{-1}$ glycerol, but it is only attributed to cell growth in medium containing $50 \mathrm{~g} \mathrm{~L}^{-1}$ glycerol where little D-GA accumulated. Fig. $1 \mathrm{~d}$ shows the $\mathrm{pH}$ in all cultures decreased with cell growth $(24 \mathrm{~h}-72 \mathrm{~h})$. After $72 \mathrm{~h}$, the $\mathrm{pH}$ in the culture with $50 \mathrm{~g} \mathrm{~L}^{-1}$ glycerol stabilized, presumably due to lack of synthesis of D-GA. The $\mathrm{pH}$ in cultures with above $100 \mathrm{~g} \mathrm{~L}^{-1}$ glycerol continued decreasing until $96 \mathrm{~h}$, and then stabilized around 3.5. These decreases in $\mathrm{pH}$ were attributable to D-GA accumulation (Fig. 1b).

A high concentration of glycerol was a prerequisite to D-GA biosynthesis in A. tropicalis, though it had a negative effect on cell growth. Previously, a fed-batch culture with glycerol feeding was applied to avert this problem ${ }^{17}$. Here we performed a twostep culture to deal with the ambivalent culture conditions between cell growth and D-GA biosynthesis. In the first stage (culture stage), the medium with low initial glycerol $\left(50 \mathrm{~g} \mathrm{~L}^{-1}\right)$ was selected for cell growth. Cells were then harvested at stationary phase, and transferred to a highly concentrated glycerol solution to induce D-GA biosynthesis, the second stage (whole-cell biocatalysis stage). Here, 
glycerol was the single substrate, and A. tropicalis was used to catalyze glycerol to D-GA. Optimization of conditions for the whole-cell biocatalysis stage are described in the following text.

\section{Optimization of conditions for the whole-cell biocatalysis process}

During the whole-cell biocatalysis stage, the DCW tended to be stable and increased only slightly in the first $12 \mathrm{~h}$ (Fig. 2). D-GA biosynthesis was triggered immediately, and the maximum D-GA yield (ca. $3.99 \mathrm{~g} \mathrm{~L}^{-1}$ ) was found after catalyzing for $36 \mathrm{~h}$. Glycerol was the only substrate in the wholecell biocatalysis stage, so cell growth was inhibited because of starvation after depletion of the nutrients that had accumulated inside cells during the previous stage. Since there is competition between cell growth and D-GA synthesis, the alleviation of the competition may be an efficient strategy for the enhancement of D-GA yield by allowing the cells to focus on catalyzing the conversion of glycerol to D-GA.

Effect of initial glycerol concentration on D-GA yield in the whole-cell biocatalysis process

A series of glycerol concentrations $(50,75$, 100,125 and $150 \mathrm{~g} \mathrm{~L}^{-1}$ ) were applied to study the effect of glycerol concentration on D-GA yield on the whole-cell biocatalysis system. Both D-GA yield and the substrate conversion rate increased with increasing glycerol concentrations (Fig. 3). D-GA yield reached $8.5 \mathrm{~g} \mathrm{~L}^{-1}$ when cultures contained $150 \mathrm{~g} \mathrm{~L}^{-1}$ glycerol. The maximum conversion rate of glycerol to D-GA (60.5\%) was observed at $125 \mathrm{~g} \mathrm{~L}^{-1}$ glycerol, with a D-GA yield of $7.65 \mathrm{~g} \mathrm{~L}^{-1}$, and a D-GA productivity of $3.4 \mathrm{~g} \mathrm{~g}^{-1} \mathrm{DCW}$. Since little cell growth was observed in the whole-cell biocatalysis process, the substrate was considered to be converted to product and consumed for maintenance of live cells. There is competition between cell growth and D-GA biosynthesis, a greater glycerol conversion rate for D-GA gained as expected was probably due to the lack of cell growth.

\section{Effect of $\mathrm{pH}$}

The $\mathrm{pH}$ decreased dramatically during fermentation due to cell growth and D-GA accumulation (Fig. 1d). This change in $\mathrm{pH}$ might in turn affect D-GA accumulation. To demonstrate the effect of $\mathrm{pH}$ on D-GA accumulation, $0.1 \mathrm{M}$ phosphate buffered saline (PBS) was applied to alleviate the $\mathrm{pH}$ reduction during the whole-cell biocatalysis process. The $\mathrm{pH}$ of the glycerol solution with or without PBS was set to be 7.0, which was the best initial $\mathrm{pH}$ observed in a previous study (data not shown). As shown in Fig. 4, the $\mathrm{pH}$ values in solutions with

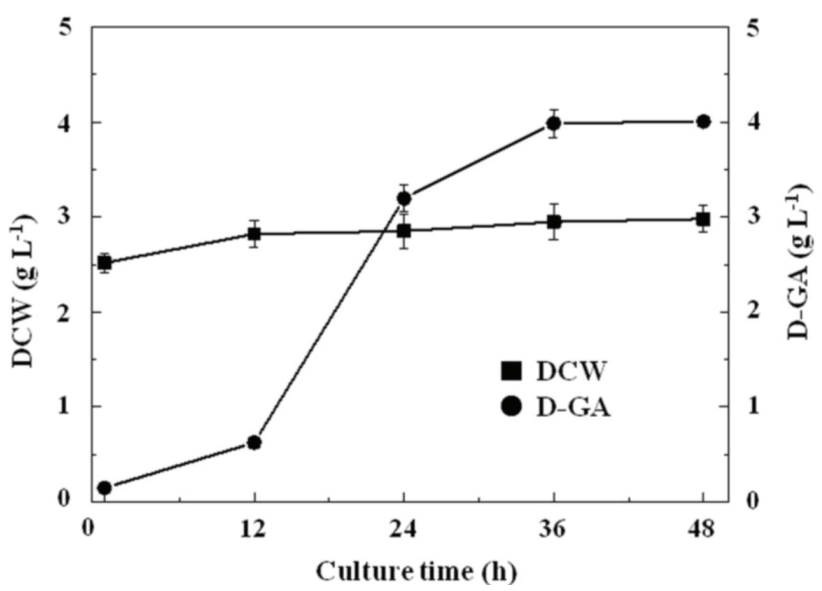

Fig. 2 - Effect of culture time on cell growth and D-GA yield

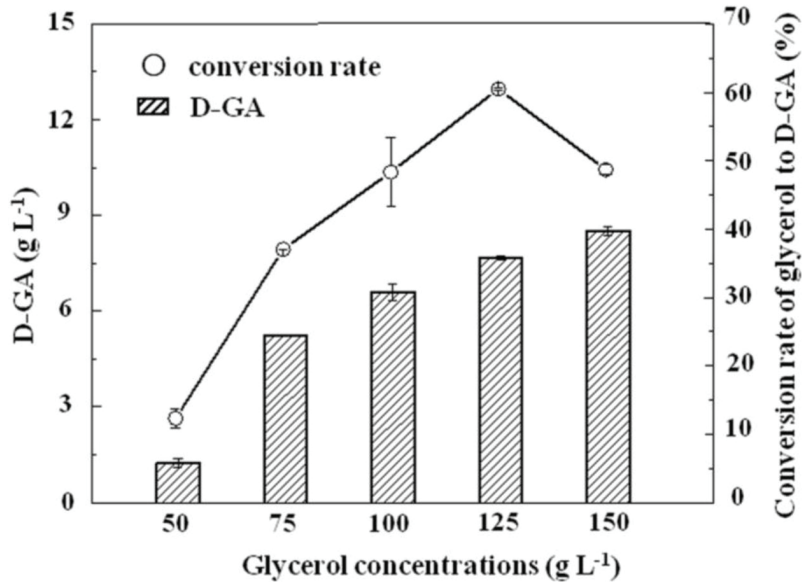

Fig. 3 - Effect of initial glycerol concentrations on D-GA yield in the whole-cell biocatalysis stage. Conversion rate of glycerol to D-GA: D-GA concentration (mol $\left.L^{-1}\right) /($ initial concentration of glycerol $\left(\mathrm{mol} \mathrm{L}^{-1}\right)$ - final concentration of glycerol $\left.\left(\mathrm{mol} \mathrm{L}^{-1}\right)\right) \cdot 100 \%$.

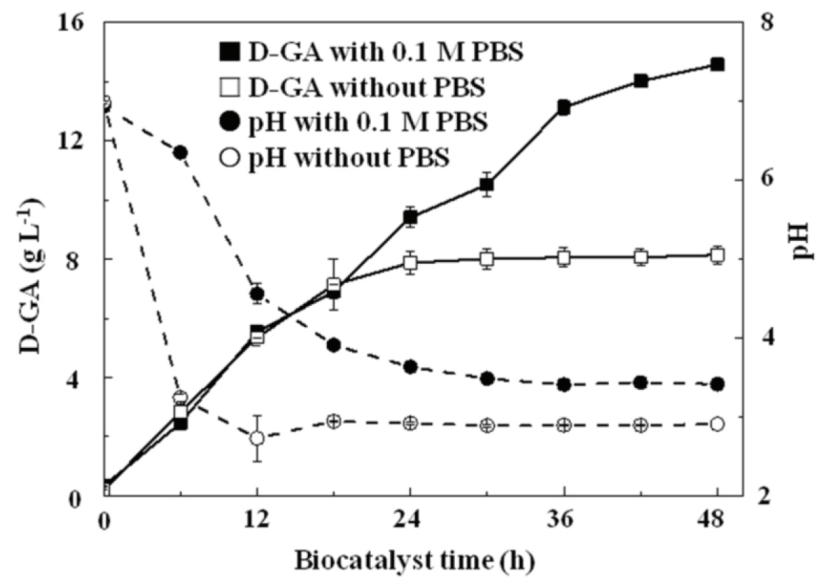

Fig. 4 - Effect of pH buffer on D-GA biosynthesis and $p H$ in culture

or without PBS dropped acutely, though those with PBS decreased slower. The $\mathrm{pH}$ in solution with $0.1 \mathrm{M}$ PBS reduced to 3.4 after $24 \mathrm{~h}$, and then stabilized around 3.5 until $48 \mathrm{~h}$. However, the $\mathrm{pH}$ in solution 
without PBS decreased to 2.9 at $18 \mathrm{~h}$, and then stabilized around 3.0. During the first $18 \mathrm{~h}$, the D-GA accumulation trends in solution with PBS were the same as the control (without PBS). Although D-GA biosynthesis stopped in the control at $24 \mathrm{~h}$, it kept synthesizing in solution with PBS until $48 \mathrm{~h}$. The D-GA yield in solution with $0.1 \mathrm{M}$ PBS was up to $14.57 \mathrm{~g} \mathrm{~L}^{-1}$ (D-GA productivity: $6.48 \mathrm{~g} \mathrm{~g}^{-1} \mathrm{DCW}$ ), which was $79 \%$ higher than that without PBS. This result suggested that D-GA formation was inhibited by a $\mathrm{pH}$ lower than 3.0. By addition of $0.1 \mathrm{M} \mathrm{PBS \text {, }}$ the $\mathrm{pH}$ decreased slower during the whole-cell biocatalysis process, and finally stabilized around 3.5, which served to prolong the D-GA biosynthesis. Therefore, $\mathrm{pH}$ controlling strategy is a potential method to further increase D-GA yield in the wholecell biocatalysis stage, especially the biocatalyst process scale-up to pilot scale in jar fermentor. In addition, the D-GA yield and D-GA productivity gained by this two-stage culture with PBS was approximately 2-fold and 4.5-fold compared to the traditional fermentation with $150 \mathrm{~g} \mathrm{~L}^{-1}$ of glycerol, respectively.

\section{D-GA produced by whole-cell biocatalysis using methanol-containing glycerol}

Methanol is a major ingredient of raw glycerol derived from the BDF industry, and it is costly to remove. Therefore, it is necessary to investigate the effect of methanol on D-GA yield in the whole-cell biocatalysis process. Glycerol $\left(125 \mathrm{~g} \mathrm{~L}^{-1}\right)$ containing different concentrations of methanol $(0,2 \%, 4$ $\%, 6 \%, 8 \%$, and $10 \%, \mathrm{v} / \mathrm{v}$ ) was used as substrate in the whole-cell biocatalysis process. Since DHA was the major by-product of D-GA yield from fermentation, it was also monitored in this experiment. As compared to glycerol without methanol, D-GA yield gained in glycerol with $2 \%$ methanol decreased by $48.8 \%$, and the ratio of D-GA to DHA reduced from 5 to 2 . (Fig. 5). However, when methanol increased from $2 \%$ to $10 \%$, D-GA yield did not decrease substantially, and the ratio of D-GA to DHA was stable at 2-3. A $29 \%$ reduction in D-GA yield was found when methanol concentrations increased from $2 \%$ to $10 \%$. These results suggested that methanol inhibited the biosynthesis of D-GA in A. tropicalis, and caused a change in product selectivity between D-GA and DHA during the wholecell biocatalysis process. However, these effects of methanol were not concentration-dependent and probably attributable to the fact that inhibition of methanol on $\mathrm{mADH}$ glycerol dehydrogenation is noncompetitive ${ }^{15} \cdot \mathrm{mADH}$ is a key enzyme in D-GA yield which catalyzes the oxidation of glycerol to glyceraldehyde ${ }^{5,19}$. The reduction in D-GA yield in the methanol-supplemented catalysis was probably due to the methanol-induced inhibition of

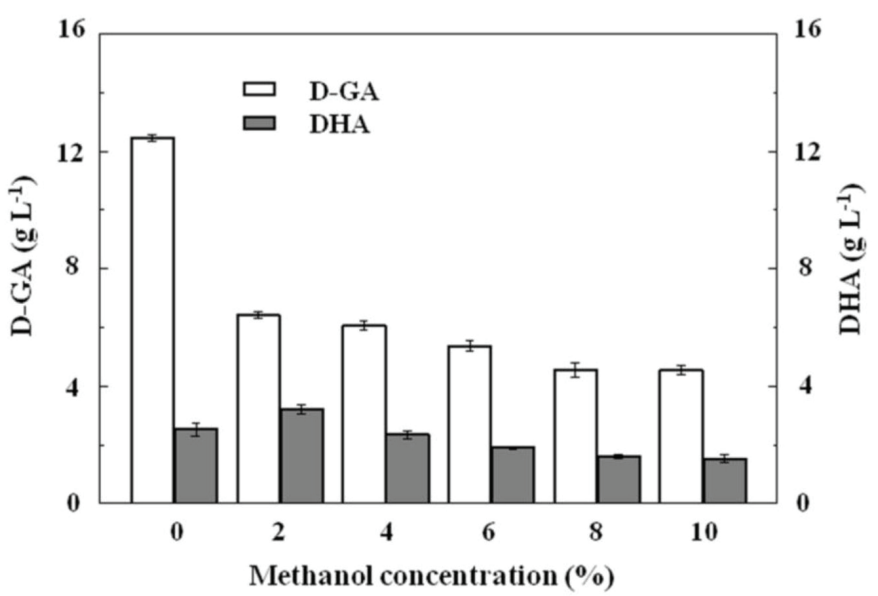

Fig. 5 - Effect of methanol on the yield of D-GA and DHA

mADH-catalyzed oxidation at a high concentration of glycerol ${ }^{15}$. Although the D-GA yield was reduced by one half relative to the methanol-free conditions, A. tropicalis was first found to be able to catalyze the conversion of glycerol to D-GA in the presence of up to $10 \%$ methanol. This tolerance to methanol is comparable to G. frateurii in fed-batch culture ${ }^{15}$.

Using $10 \%$ methanol-containing glycerol as substrate, D-GA yield remained $4.5 \mathrm{~g} \mathrm{~L}^{-1}$ with whole-cell biocatalysis. As both cell growth and D-GA biosynthesis were inhibited by methanol ${ }^{15}$, glycerol without methanol was applied in the first stage to avoid the inhibition of methanol on cell growth; then raw glycerol containing methanol up to $10 \%$ could be used in the second stage to reduce the cost of materials. Taken together, these results suggested that the two-stage strategy with a wholecell biocatalyst for D-GA yield by $A$. tropicalis was an efficient method for producing D-GA from methanol-containing glycerol. The potential of using raw glycerol as substrate would decrease the cost of raw material, and the simple composition of D-GA broth from the whole-cell biocatalysis make the following separation easier and cheaper. In addition, the equipment required for this two-step culture strategy is all normal equipment for fermentation industry, which make industrial yield easy. Therefore, this is a promising technology for producing D-GA at low cost. Further studies on optimization of conditions for the whole-cell biocatalysis using raw glycerol as a substrate, especially $\mathrm{pH}$ control, will be necessary to enhance D-GA yield by the twostage culture strategy, which is part of our on-going work.

\section{Conclusions}

A novel two-stage culture including whole-cell biocatalysis was developed to deal with the conflict between cell growth and D-GA yield at high con- 
centrations of glycerol. Approximately 2-fold D-GA yield and 4.5-fold D-GA productivity were gained by this two-stage strategy compared to the traditional fermentation with $150 \mathrm{~g} \mathrm{~L}^{-1}$ glycerol. This strategy also worked well when using methanol-containing glycerol as a substrate. Though the D-GA yield had reduced by one half relative to the methanol-free conditions, A. tropicalis was first found to be able to convert glycerol into D-GA in the presence of $10 \%$ methanol. These findings have important implications for the production of D-GA by biocatalyst process, including culture conditions optimization, scale-up strategy, and cost reduction.

\section{ACKNOWLEDGEMENTS}

This work was supported by National Natural Science Foundation of China (41606177), Industry-University Cooperation Project of Fujian Province (2015N5006), Young and Middle-aged Teachers Education Scientific Research Project of Fujian Province (JA15406).

\section{Reference}

1. Fukuoka, T., Ikeda, S., Habe, H., Sato, S., Sakai, H., Abe, M., Kitamoto, D., Sakaki, K., Synthesis and interfacial properties of monoacyl glyceric acids as a new class of green surfactants, J. Oleo. Sci. 61 (2012) 343.

doi: https://doi.org/10.5650/jos.61.343

2. Habe, H., Fukuoka, T., Kitamoto, D., Sakaki, K., Biotechnological production of D-glyceric acid and its application, Appl. Microbiol. Biotechnol. 84 (2009) 445. doi: https://doi.org/10.1007/s00253-009-2124-3

3. Habe, H., Sato, H., Fukuoka, T., Kitamoto, D., Sakaki, K., Effect of glyceric acid calcium salt on the viability of ethanol-dosed gastric cells, J. Oleo. Sci. 60 (2011) 585. doi: https://doi.org/10.5650/jos.60.585

4. Eriksson, C. J., Saarenmaa, T. P., Bykov, I. L., Heino, P. U., Acceleration of ethanol and acetaldehyde oxidation by D-glycerate in rats, Metabolism 56 (2007) 895. doi: https://doi.org/10.1016/j.metabol.2007.01.019

5. Habe, H., Sato, S., Fukuoka, T., Kitamoto, D., Yakushi, T., Matsushita, K., Sakaki, K., Membrane-bound alcohol dehydrogenase is essential for glyceric acid production in Acetobacter tropicalis, J. Oleo. Sci. 60 (2011) 489. doi: https://doi.org/10.5650/jos.60.489

6. Handa, S. S., Sharma, A., Chakraborti, K. K., Natural products and plants as liver protecting drugs, Fitoterapia 57 (1986) 307.

7. Habe, H., Fukuoka, T., Kitamoto, D., Sakaki, K., Biotransformation of glycerol to D-glyceric acid by Acetobacter tropicalis, Appl. Microbiol. Biotechnol. 81 (2009) 1033. doi: https://doi.org/10.1007/s00253-008-1737-2

8. Habe, H., Fukuoka, T., Kitamoto, D., Sakaki, K., Application of electrodialysis to glycerate recovery from a glycerol containing model solution and culture broth, J. Biosci. Bioeng. 107 (2009) 425.

doi: https://doi.org/10.1016/j.jbiosc.2008.12.008

9. Fukuda, H., Hama, S., Tamalampudi, S., Noda, H., Wholecell biocatalysts for biodiesel fuel production, Trends Biotechnol. 26 (2009) 668. doi: https://doi.org/10.1016/j.tibtech.2008.08.001

10. Feng, G., Wu, H., Li, X., Lai, F., Zhao, G., Yang, M., Liu, $H$., A new, efficient and highly-regioselective approach to synthesis of 6-O-propionyl-D-glucose by using whole-cell biocatalysts, Biochem. Eng. J. 95 (2015) 56. doi: https://doi.org/10.1016/j.bej.2014.12.008

11. Jin, Z., Liang, S., Zhang, X., Han, S., Ren, C., Lin, Y., Zheng, $S$., Synthesis of fructose laurate esters catalyzed by a CALB-displaying Pichia pastoris whole-cell biocatalyst in a non-aqueous system, Biotechnol. Bioprocess Eng. 18 (2013) 365 . doi: https://doi.org/10.1007/s12257-012-0511-6

12. Shen, L., An, Z., Li, Q., Yao, C., Peng, Y., Wang, Y., Lai, R., Deng, $X$., $H e, N$., Three-stage fermentation and kinetic modeling of bioflocculant by Corynebacterium glutamicum, Chin. J. Chem. Eng. 23 (2015) 219. doi: https://doi.org/10.1016/j.cjche.2014.11.012

13. Peng, C., Huang, J., Hu, S., Zhao, W., Yao, S., Mei, L., A Two-stage $\mathrm{pH}$ and temperature control with substrate feeding strategy for production of gamma-aminobutyric acid by Lactobacillus brevis CGMCC 1306, Chin. J. Chem. Eng. 21 (2013) 1190.

doi: https://doi.org/10.1016/S1004-9541(13)60568-6

14. Feng, X., Ding, Y., Xian, M., Xu, X., Zhang, R., Zhao, G., Production of optically pure D-lactate from glycerol by engineered Klebsiella pneumoniae strain, Bioresour. Technol. 172 (2014) 269. doi: https://doi.org/10.1016/j.biortech.2014.09.074

15. Sato, S., Morita, N., Kitamoto, D., Yakushi, T., Matsushita, $K$., Habe, $H$., Change in product selectivity during the production of glyceric acid from glycerol by Gluconobacter strains in the presence of methanol, AMB Express 3 (2013) 1. doi: https://doi.org/10.1186/2191-0855-3-20

16. Sato, S., Kitamoto, D., Habe, H., Chemical mutagenesis of Gluconobacter frateurii to construct methanol-resistant mutants showing glyceric acid production from methanol-containing glycerol, J. Biosci. Bioeng. 117 (2014) 197. doi: https://doi.org/10.1016/j.jbiosc.2013.07.004

17. Habe, H., Shimada, Y., Yakushi, T., Hattori, H., Ano, Y., Fukuoka, T., Kitamoto, D., Itagaki, M., Watanabe, K., Yanagishita, H., Matsushita, K., Sakaki, K., Microbial production of glyceric acid, an organic acid that can be mass produced from glycerol, Appl. Environ. Microbiol. 75 (2009) 7760. doi: https://doi.org/10.1128/AEM.01535-09

18. Liu, Z., Hu, Z., Zheng, Y., Shen, Y., Optimization of cultivation conditions for the production of 1,3-dihydroxyacetone by Pichia membranifaciens using response surface methodology, Biochem. Eng. J. 38 (2008) 285. doi: https://doi.org/10.1016/j.bej.2007.07.015

19. Habe, H., Shimada, Y., Fukuoka, T., Kitamoto, D., Itagaki, M., Watanabe, K., Yanagishita, H., Yakushi, T., Matsushita, K., Sakaki, K., Use of a Gluconobacter frateurii mutant to prevent dihydroxyacetone accumulation during glyceric acid production from glycerol, Biosci. Biotechnol. Biochem. 74 (2010) 2330. doi: https://doi.org/10.1271/bbb.100406 